\title{
CARACTERIZAÇÃO DA VISITAÇÃO NO PARQUE ESTADUAL DOS TRÊS PICOS, RJ
}

\author{
Bárbara Pelacani ${ }^{1}$ \\ Euzimar Silva ${ }^{2}$ \\ Tatiana Horta ${ }^{3}$ \\ Thabta Mattos ${ }^{4}$
}

\section{Resumo}

O ecoturismo é o segmento de viagens que mais cresce no mundo, sendo que os espaços das Unidades de Conservação são importantes atrativos neste contexto. Acredita-se que o incremento da visitação deve ser acompanhado pelo planejamento das atividades, a fim de mitigar os impactos socioambientais negativos e ressaltar os pontos positivos. O presente estudo objetivou caracterizar a visitação do Parque Estadual dos Três Picos no Rio de Janeiro. Para tal, utilizou-se a análise das fichas de cadastro de visitantes preenchidas nos núcleos do Parque entre 2003 e 2012. Visando aprimorar este levantamento foi proposto um agrupamento das áreas do parque que possuem características e atividades de uso público similares. Resultando numa classificação em setores (Educação Ambiental, Administrativo, Águas, Esporte e Montanha). Os resultados revelaram uma tendência de aumento da visitação ao longo do tempo, além de um padrão de sazonalidade da visitação durante o ano. Foi constatado maior uso público nos meses mais quentes, entre dezembro e fevereiro, nos núcleos com área banho (Jacarandá e Vale da Revolta), e nos meses mais frios, entre maio e agosto, no núcleo Três Picos. As informações geradas no presente estudo são o primeiro passo para revelar o potencial ecoturístico do PETP, e consequentemente fornecer base científica à gestão estratégica direcionada ao uso público da Unidade.

Palavras Chave: Parque Estadual dos Três Picos; uso público; caracterização da visitação.

\begin{abstract}
Ecotourism is the fastest growing sector in the travel industry, and conservation entities are the main representatives in this area. It is believed an increase in visitation to these entities should be accompanied by the planning of activities in order to mitigate negative socio-environmental impacts while featuring the positives of ecotourism. The objective of the present study is to characterize the visitation of the Três Picos State Park (PETP) in Rio de Janeiro. This study uses the analysis of visitor registration utilized at the park centers from 2003 thru 2012. The park areas characterized by similar activities and aspects of public use were grouped together to enhance the analysis. The result was a classification into four sectors (Environmental Education, Administrative, Waters, Sport and Mountain). The results revealed an increase in visitation throughout the time period, aside from the seasonality observed during the year. It was found that during the hotter months, between December and February, the most public use occurred in the locations with bathing areas (Jacarandá and Vale da Revolta), and in the colder months, between May and August, in the Três Picos area. The information generated in the present study is the first step in revealing the ecotourism

\footnotetext{
1 Parque Estadual dos Três Picos (PETP). Instituto Terra de Preservação Ambiental (ITPA). E-mail: petp.scc@itpa.org.br

${ }^{2}$ Parque Estadual dos Três Picos (PETP). E-mail: euzimar_gomes@ yahoo.com.br

${ }^{3}$ Parque Estadual dos Três Picos (PETP). ITPA. E-mail: petp.usopublico@itpa.org.br

${ }^{4}$ Parque Estadual dos Três Picos (PETP). ITPA. E-mail: petp.monitor@itpa.org.br
} 
potential of PETP and providing a scientific basis for the strategic management directed towards the public use of this entity.

Keywords: Três Picos State Park; public use; characterization of visitation

\section{Introdução}

O ecoturismo é o segmento de viagens que mais cresce no mundo, fato certamente relacionado à crescente preocupação da sociedade com o meio ambiente (OLIVEIRA, et al, 2010). Os espaços das unidades de conservação (UCs), vêm despertando o interesse deste segmento, o que gera demandas do estabelecimento de normas para que tais atividades sejam praticadas adequadamente, suprindo a expectativa do visitante e cumprindo com os objetivos de manejo. O uso público, termo que engloba a visitação, é um dos principais objetivos de algumas categorias de UCs. Esta atividade é considerada uma forma de uso indireto dos recursos, buscando o desenvolvimento de práticas de educação e interpretação ambiental, de recreação em contato com a natureza e de turismo ecológico (SNUC, 2000).

Ao promover o contato da sociedade com as áreas naturais protegidas, é gerado um maior interesse por questões ligadas ao meio ambiente. Por exemplo, ao tomar contato com as UCs, os turistas e moradores têm a oportunidade de entender a importância da conservação e os múltiplos benefícios para a sociedade, usufruindo adequadamente do bem público e disseminando uma imagem positiva deste tipo de iniciativa. Deste modo, as unidades devem estar preparadas para lidar com este desafio, promovendo uma gestão eficiente de seus atrativos (PADINI, 2012).

Além disso, o incremento da visitação deve ser acompanhado pelo planejamento das atividades ecoturísticas, a fim de mitigar os impactos socioambientais negativos e ressaltar os pontos positivos consequentes da visitação (PIRES; MUNIZ, 2010). Estudos que caracterizam visitação e perfil do visitante são de suma importância para a elaboração de programas específicos de uso público em UCs, assim como para auxiliar gestores a lidarem com o aumento da visitação (EAGLES et. al. 2002).

No estado do Rio de Janeiro, as UCs de proteção integral são administradas pelo INEA (Instituto Estadual do Ambiente - RJ) e estão passando por grandes avanços nos últimos anos. São inúmeras ações relacionadas à criação, implantação e manejo destas unidades, onde há investimentos consideráveis em planos de manejo, regularização fundiária, infraestrutura, contratação de pessoal (como os 220 guarda-parques concursados), implantação de Unidades de Polícia Ambiental (UPAm) e, mais especificamente, o fortalecimento do uso público, através de ações para o incremento da visitação nestas UCs, orientado por um instrumento legal específico que regula suas atividades, o Decreto Estadual n 42.483/ 2010 (LORENZETTO, 2013).

O Parque Estadual dos Três Picos (PETP) é a maior UC de proteção integral do estado do Rio de Janeiro. O nome atribuído evoca os afloramentos rochosos dos Três Picos, imponente conjunto montanhoso granítico com 2.316 metros de altitude, ponto culminante de toda a Serra do Mar no estado. O Parque foi criado a partir Decreto-Lei ${ }^{\circ} 31.343$ de 05 de junho de 2002, com aproximadamente 58.790 hectares, dos quais dois terços situam-se no 
município de Cachoeiras de Macacú, onde se localiza a sede administrativa. O PETP estendese ainda pelos municípios de Nova Friburgo, Teresópolis, Guapimirim e Silva Jardim.

No PETP, devido à ampla variação de altitude dentro da unidade (de 100 a $2.316 \mathrm{~m}$ ) podem ser observadas formações vegetais diversas como a floresta ombrófila densa, as matas de neblina e os campos de altitude. Além disso, o parque é um importante refúgio de inúmeras espécies da fauna do Bioma Mata Atlântica, especialmente os grandes mamíferos, como a onça parda, a lontra, a jaguatirica, e constitui um dos principais pontos para observação de aves do Brasil (INEA, 2009).

O presente estudo tem como objetivo caracterizar a visitação nos núcleos do PETP, identificando padrões de distribuição dos usuários ao longo dos meses nos núcleos, com avaliação do cadastramento de visitantes.

\section{Materiais e métodos}

\section{a) Caracterização da área}

O PETP encontra-se dividido em núcleos, sendo estes: Jequitibá - em Cachoeiras de Macacú; Três Picos - em Nova Friburgo; Jacarandá e Vale da Revolta - ambos em Teresópolis. Estes núcleos apresentam inúmeros atrativos com inestimável beleza cênica, áreas de floresta em excelente estado conservação, um grande número de nascentes, rios e cachoeiras, resultando numa ampla variedade de atrativos para o uso público, o que torna o parque um dos principais atrativos turísticos da região (INEA, 2009).

Este estudo foi realizado em todos os núcleos do PETP supracitados. O trabalho se limitou na caracterização da visitação nesses núcleos excetuando os municípios de Silva Jardim e Guapimirim que, embora possuam atrativos de grande potencial, não possuem controle da visitação.

O núcleo Jequitibá abriga a Sede Administrativa do Parque, Centro de Visitantes, Trilha Interpretativa do Jequitibá e Trilha do Mirante e tem como principal atrativo um exemplar milenar do Jequitibá-rosa (Cariniana legalis) com aproximadamente 1000 anos de idade e 19 m de circunferência (Figura 01). Outros atrativos próximos a este núcleo são: a Trilha do Antigo Leito Ferroviário, a Trilha da Pedra do Faraó, Ruína do Aqueduto Fazenda Santa Fé e as Trilhas do Barão (de Castália a São Lourenço). 

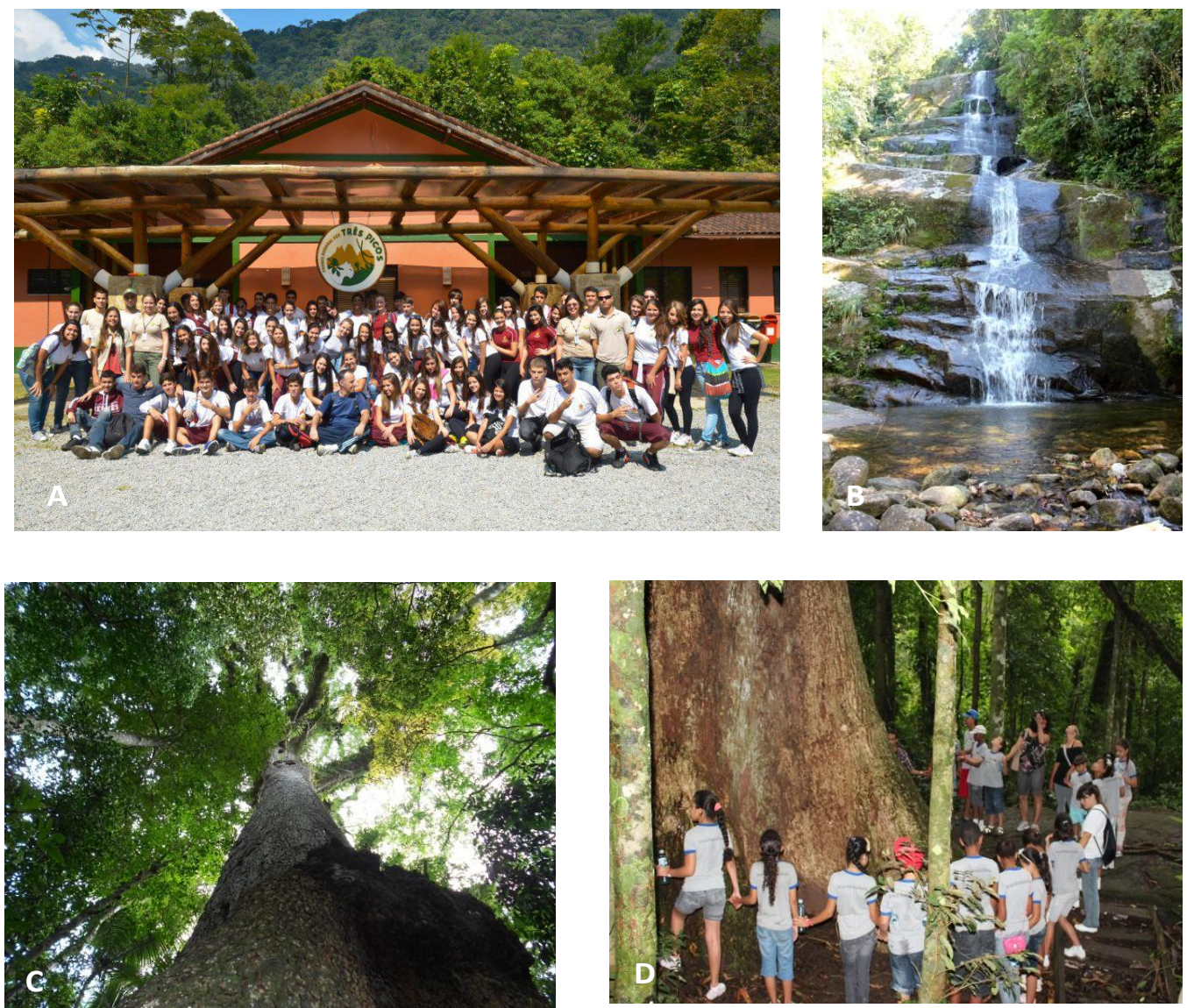

Figura 01. A - Grupo escolar reunido no centro de visitantes do núcleo Jequitibá. B - Cachoeira das Sete Quedas. C - Jequitibá-rosa (Cariniana legalis). D - Grupo escolar abraçando o jequitibá. Fonte: ITPA.

Também ocorre o cross country em algumas travessias. Além disso, em Cachoeiras de Macacú, podem ser visitadas diversas cachoeiras como Sete Quedas e Furna da Onça e vários poços naturais que são intensamente visitados no verão, tais como Lagoa Azul e Samambaia (INEA, 2009).

O núcleo Três Picos está localizado em Nova Friburgo e abriga um dos mais extraordinários conjuntos de montanhas de todo o país, como os "Três Picos". Devido ao grande desnível das escarpas das fendas que cortam os maciços, é uma referência internacional da escalada em grandes paredes, com vias de até 900 metros. Os principais atrativos deste núcleo são as grandes formações de granito, como o Capacete, Cabeça do Dragão, Caixa de Fósforos, Ronca Pedra e Vale dos Deuses. Também ocorre, além de caminhadas (trekking), o cross country em algumas travessias (INEA, 2009).

\footnotetext{
${ }^{5}$ Cross country é também conhecido como corrida "corta-mato", às vezes referido como cross ou crosse, é um desporto de equipe em que os atletas competem numa corrida em terreno aberto ou acidentado (Nota dos autores).
} 

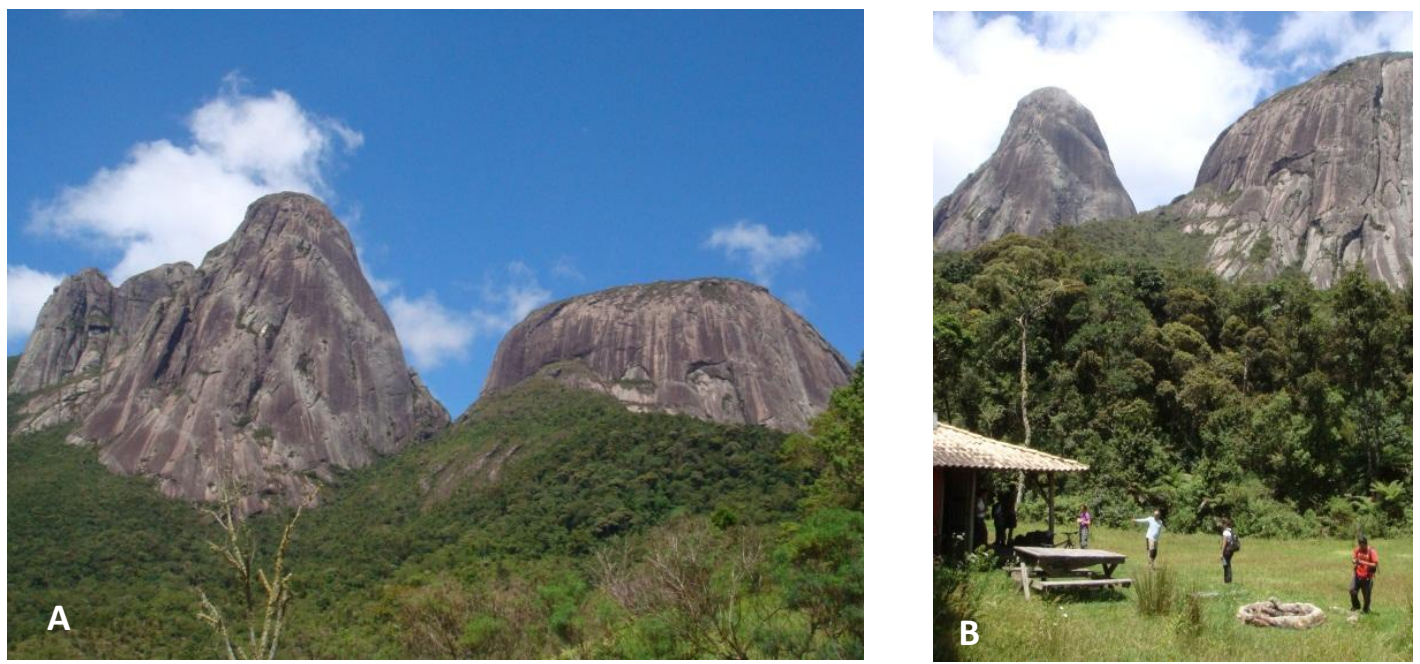

Figura 02. A - Formação rochosa dos Três Picos. B - Área de camping no núcleo Três Picos. Fonte: ITPA.

Os núcleos Jacarandá e Vale da Revolta estão localizados em Teresópolis. Ambos possuem rios para banhistas, campo de futebol, áreas de lazer e algumas trilhas para caminhada, como a Trilha Vale da Revolta - Jacarandá (Figuras 03 e 04). Em Teresópolis encontra-se o Vale dos Frades, numa região muito visita por montanhistas e escaladores. Nesses núcleos encontram-se os atrativos Dois Bicos, Torres de Bonsucesso, Pedra do Elefante e a Cachoeira dos Frades (INEA, 2009). No núcleo Vale da Revolta será implantada uma subsede do Parque, com infraestrutura de administração, centro de visitantes, casa do chefe, pórtico, guarita, área de lazer, camping, revitalização da estrada existente e paisagismo em geral, inclusive no entorno dos espelhos e cursos d’água existentes (RIO DE JANEIRO, 2013).
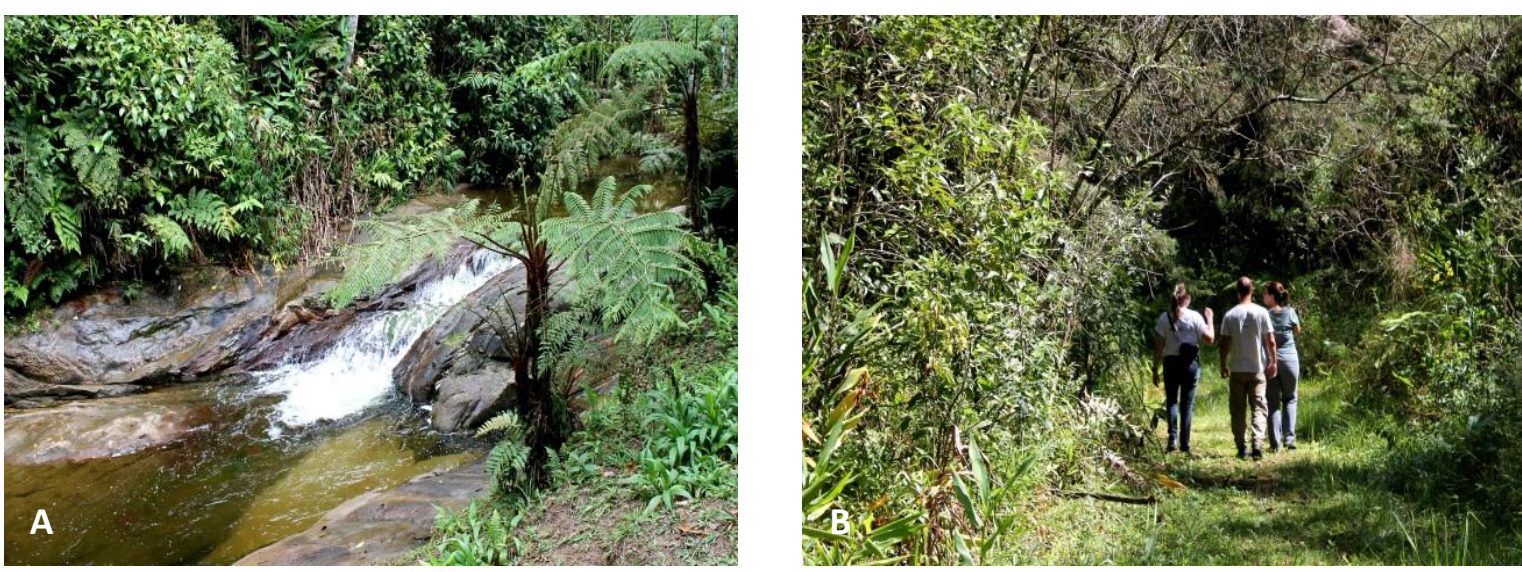

Figura 03. A - Trecho do rio apropriado para banho dos visitantes. B - Trecho de caminhada leve no núcleo. Fonte: ITPA. 

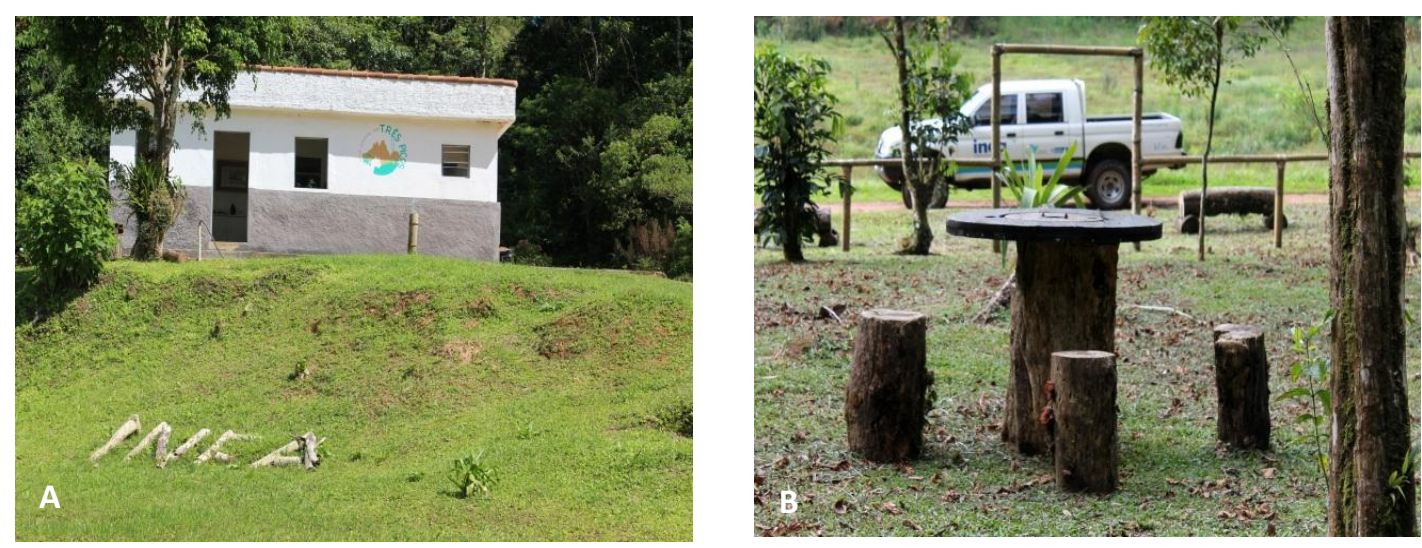

Figura 04. A - Casa de apoio no núcleo Vale da Revolta. B - Área de descanso no núcleo Vale da Revolta. Fonte: ITPA.

\section{b) Coleta das informações}

No núcleo Jequitibá o controle dos visitantes foi feito através de preenchimento de ficha de cadastro, coletando-se informações como tamanho do grupo, data e origem da visita e atividade realizada localizada no Centro de Visitantes. No Três Picos, o controle ocorreu por meio de Fichas de Cadastro deixadas nas pousadas e abrigos, além do registro realizado por guarda-parques em campo e no núcleo. No Jacarandá e no Vale da Revolta, o cadastramento foi realizado pelos vigilantes, na única entrada de acesso de cada núcleo.

\section{c) Análise de dados}

Foram levantados os dados de cadastro de visitantes da unidade referentes ao período de 2003 a 2012. Essas fichas não seguem uma padronização, com diferentes informações sendo coletadas, existindo variação entre os núcleos e os períodos de coleta de dados. Independentemente destas diferenças, fez-se a contagem e a caracterização dos visitantes, sendo realizada através da observação destas fichas e de fontes de documentos da unidade. Os dados foram agrupados por anos e núcleos, calculando-se a média da visitação mensal para cada um deles, efetuando-se análises posteriores.

\section{Resultados}

O PETP proporciona diversificadas experiências aos seus usuários e a caracterização deste cenário pode ser observada e analisada a partir de dados de cadastramento de visitantes, que expõem sua frequência e distribuição, como apresentado a seguir. Os gráficos foram elaborados da seguinte forma: no gráfico da Figura 05 foi demonstrada a visitação no Parque, nos anos de 2003 a 2012, com separação da visitação por núcleo. Desta forma, foi possível perceber a variação da visitação total e em cada núcleo do parque. 


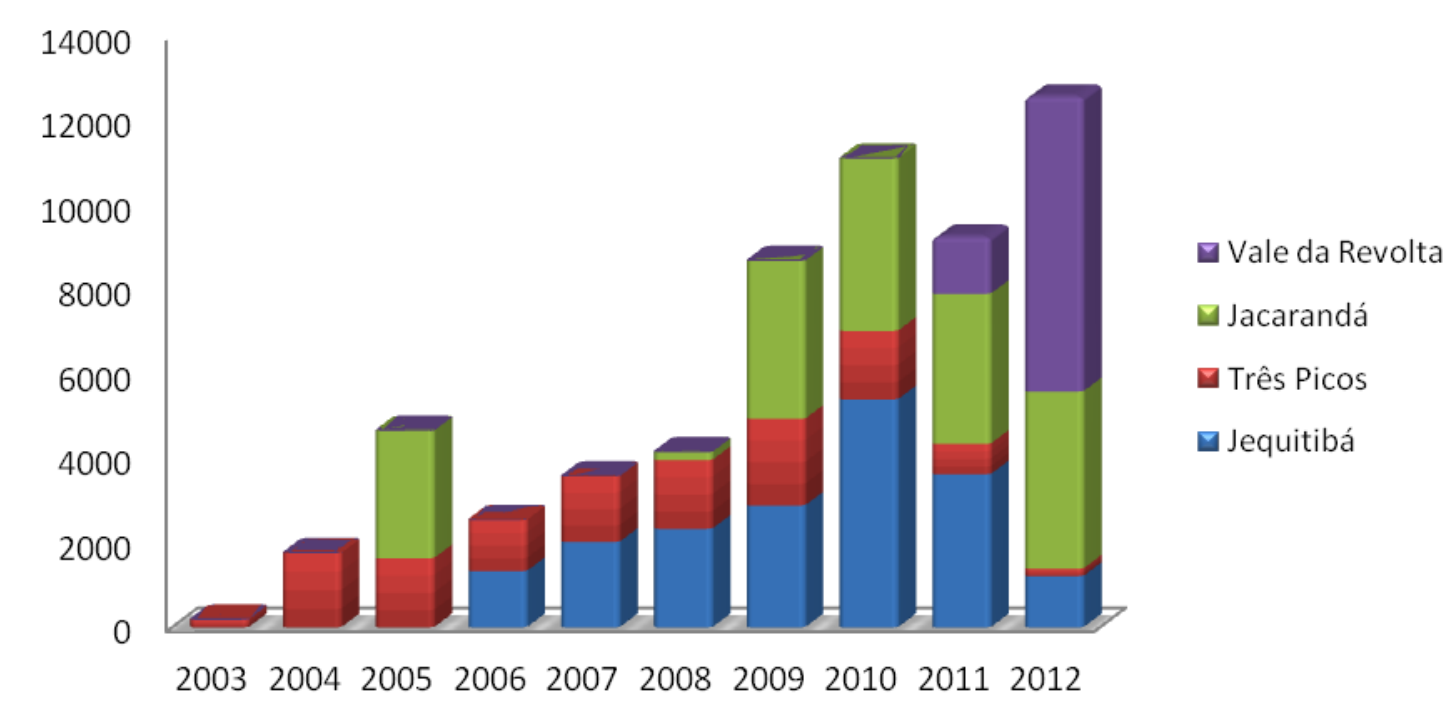

Figura 05. Visitação anual registrada nos quatro núcleos do Parque Estadual dos Três Picos (2003 a 2012)

O monitoramento da visitação no PETP iniciou-se no ano de 2003, de forma incipiente no núcleo Três Picos. Somente no ano seguinte foram observados números expressivos para o núcleo. Em 2005 foi iniciado o cadastramento no Jacarandá, com intervalo nos anos de 2006 e 2007, sendo retomado em 2008, ainda expressando números aquém do esperado. O núcleo Jequitibá iniciou seu cadastro no ano de 2006, passando a ter monitoramento contínuo como ocorreu no Três Picos. O Vale da Revolta foi aberto à visitação em 2011, com cadastramento, resultando num forte incremento no número de visitantes total do PETP, como pode ser observado no gráfico acima.

Em 2010 foi inaugurado o Centro de Visitantes do Jequitibá, o que gerou um incremento notável na visitação, com dois mil usuários a mais que em 2009. Acredita-se em uma tendência natural de aumento progressivo do número de usuários ao longo dos anos. Entretanto, o observado em 2011 foi um decréscimo, com uma queda de dois mil visitantes, que pode ser explicado por problemas logísticos no registro de usuários dos núcleos Jequitibá e Três Picos, como a redução no quadro de funcionários.

Os núcleos Jacarandá e Vale da Revolta foram os que exibiram maior visitação, chegando a somar cerca de 11 mil visitantes no ano de 2012. O que se destaca nestes dois casos é que a visitação ocorreu em massa e o cadastramento foi bem controlado. Com a implantação das estruturas previstas no Vale da Revolta, acredita-se que a visitação será consolidada e que atingirá níveis ainda maiores. Já os valores de visitação no Três Picos, caracterizado por elevado potencial ecoturístico especializado (montanhistas e escaladores), são os menos expressivos, sua maior visitação ocorreu no ano de 2009, com 2.056 visitantes.

Nos gráficos da Figura 06 constam os dados de visitação média mensal em cada núcleo, sendo possível visualizar as variações sazonais ocorridas na UC. 


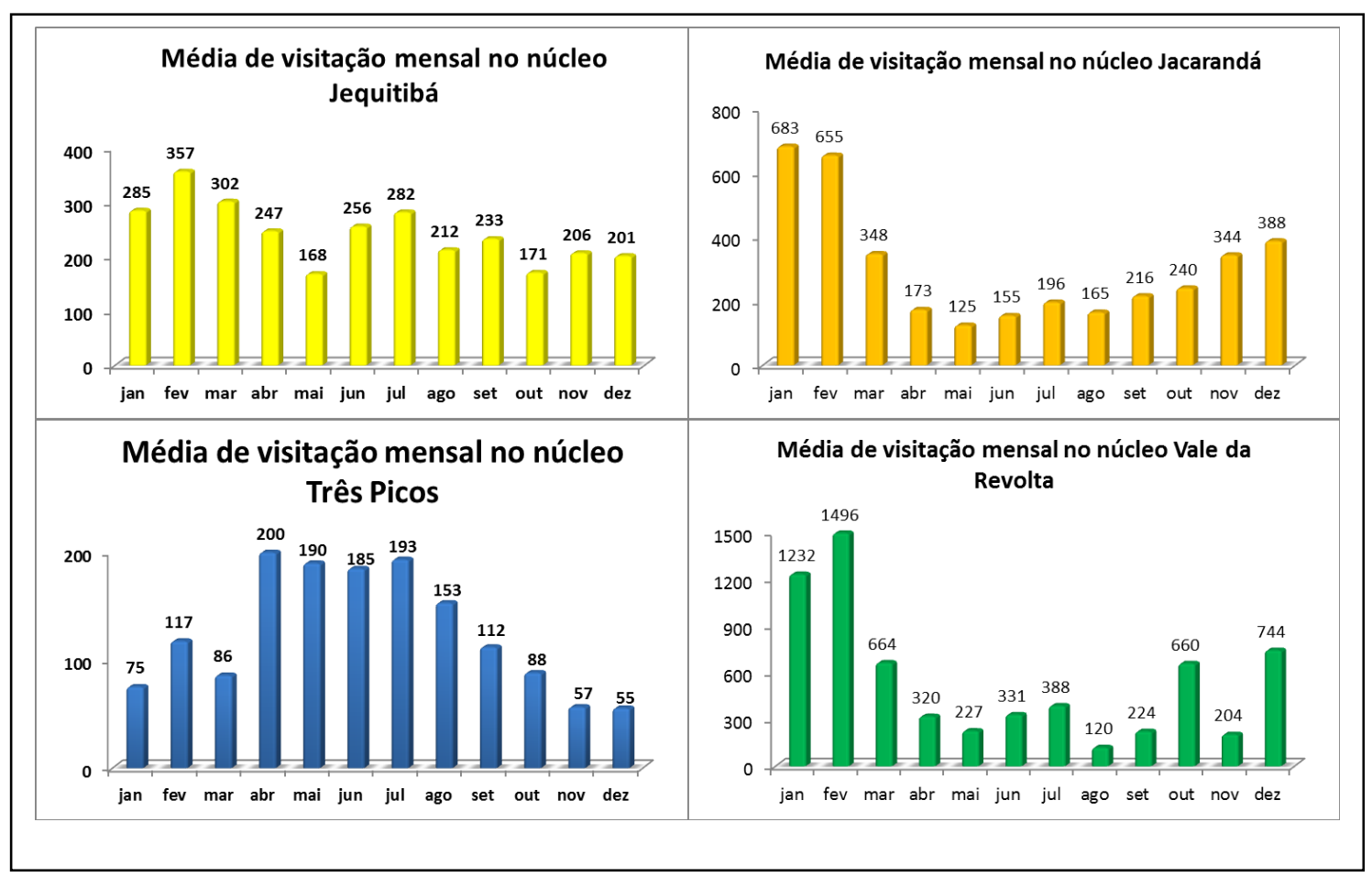

Figura 06. Média mensal de visitantes nos quatro núcleos do PETP (2003 a 2012)

Observa-se que a visitação no Jequitibá apresentou pouca variação ao longo do ano, com pequenos picos nos meses de férias escolares. No Três Picos, o gráfico exibe sazonalidade, com maior intensidade de visitação entre abril e julho, estação menos chuvosa, mais favorável para a prática de atividades como o montanhismo, a escalada e o camping. No Jacarandá e no Vale da Revolta a visitação também se apresenta de forma irregular ao longo do ano, com maior fluxo em janeiro e fevereiro, época quente do ano, propícia ao banho de rio e cachoeira. Além disso, observa-se um pico no mês de fevereiro em todos os núcleos, que pode ser justificado em função do feriado de carnaval.

No Jequitibá a maior parte dos visitantes é proveniente de Cachoeiras de Macacú, da região metropolitana e das baixadas litorâneas. A visitação ocorre em grupos que permanecem por cerca de quatro horas na UC, em sua maioria, grupos escolares em busca de interpretação ambiental. No Três Picos, o principal público encontra-se na faixa média de 20 a 40 anos e é formado por pequenos grupos. Procedentes, em grande parte, de outros municípios do Rio de Janeiro, buscam recreação ao ar livre e novos desafios, sendo que as visitas duram entre 1 e 2 dias. Tanto no Jequitibá, quanto no Três Picos há registros de visitantes de outros estados e países, sendo mais recorrente neste último. O Jacarandá e o Vale da Revolta possuem uma similar caracterização da visitação, sendo os usuários moradores das comunidades do entorno, que utilizam a área para lazer, atividades esportivas e práticas religiosas, apresentando um padrão de visitação com grupos relativamente grandes (de 6 a 20 pessoas).

Campos (2007) afirma que o controle de visitantes feito nos núcleos do PETP é extremamente válido, pois cada um deles representa uma amostra do setor do parque. $\mathrm{O}$ autor cita o caso do Pico da Caledônia como tendo, possivelmente, sazonalidade similar à encontrada no Três Picos, pois são áreas onde são praticadas atividades de montanha. Alguns 
parques exibem esta setorização, como no caso do Parque Nacional do Itatiaia-RJ, com os setores Parte Alta (montanha) e Parte Baixa (com centro de visitantes e atrativos como rios e cachoeiras) (ICMBIO, 2013). Outro exemplo é o do Parque Nacional La Campana (Valparaíso - Chile), que se divide em Setor Cajón Grande (com poços para banho), Setor Granizo (mais visitado do parque, único ponto de onde partem trilhas para atingir o cume do cerro La Campana) e Setor Ocoa (maior setor do parque, com grandes distancias entre os pontos de interesse, sendo caminhadas de maior nível de dificuldade) (FRANCIOLI; MUÑOZ, 2002). Além de ser uma divisão natural devido á sua localização, cada setor se caracteriza por possuir semelhanças físicas e ambientais, propiciando o desenvolvimento de atividades e atrativos distintos.

Visando integrar as atividades de uso público praticadas no PETP, foi estabelecida uma setorização que agrupa núcleos e atrativos explorados no parque (Quadro I).

Quadro I. Agrupamento por setores de acordo com as características e atividades praticadas em cada núcleo e atrativo

\begin{tabular}{|c|c|c|}
\hline Setor & Núcleos e atrativos & Características \\
\hline \multirow{2}{*}{$\begin{array}{l}\text { Setor de } \\
\text { Educação } \\
\text { Ambiental }\end{array}$} & Jequitibá & $\begin{array}{l}\text { Infraestrutura e funcionários } \\
\text { capacitados }\end{array}$ \\
\hline & Vale da Revolta & $\begin{array}{l}\text { Infraestrutura será implantada e } \\
\text { funcionários capacitados }\end{array}$ \\
\hline \multirow{2}{*}{$\begin{array}{l}\text { Setor } \\
\text { Administrativo }\end{array}$} & Jequitibá & Sede administrativa \\
\hline & Vale da Revolta & Sub-sede será implantada \\
\hline \multirow[t]{4}{*}{ Setor das Águas } & $\begin{array}{l}\text { Jequitibá, Cachoeira das } \\
\text { Sete Quedas e Furna da } \\
\text { onça e Poços em Cachoeiras } \\
\text { de Macacu }\end{array}$ & Cachoeiras, poços e rios para banho \\
\hline & $\begin{array}{l}\text { Jacarandá e Cachoeira dos } \\
\text { Frades }\end{array}$ & Cachoeiras e rios para banho \\
\hline & Vale da Revolta & Rio para banho \\
\hline & Nova Friburgo & Cachoeiras e poços para banho \\
\hline $\begin{array}{l}\text { Setor de } \\
\text { Esportes }\end{array}$ & Todos & $\begin{array}{l}\text { Caminhada, mountain bike, futebol e } \\
\text { rapel }\end{array}$ \\
\hline \multirow[t]{2}{*}{$\begin{array}{l}\text { Setor de } \\
\text { Montanha }\end{array}$} & $\begin{array}{l}\text { Três Picos e Pico da } \\
\text { Caledônia }\end{array}$ & $\begin{array}{l}\text { Caminhadas de médio e alto nível e } \\
\text { escaladas }\end{array}$ \\
\hline & $\begin{array}{l}\text { Pedra do Elefante, Torres de } \\
\text { Bonsucesso e Mulher de } \\
\text { Pedra }\end{array}$ & $\begin{array}{l}\text { Caminhadas de médio e alto nível e } \\
\text { escaladas }\end{array}$ \\
\hline
\end{tabular}

\section{Conclusões}

A visitação no PETP é sazonal, sendo maior nos períodos de férias escolares e carnaval. Apresenta variações de acordo com o núcleo estudado, como por exemplo o período de alta temporada do montanhismo no Três Picos que se contrapõe à baixa temporada do turismo dos usuários em busca banho de rio e cachoeira no Jacarandá e no Vale da Revolta. O núcleo Jequitibá possui alta visitação de grupos ao longo de todo o ano, especialmente os escolares. Embora os dados de visitação do PETP apresentem valores expressivos, acredita-se 
que eles sejam substancialmente maiores do que os registrados, levando se em conta que a UC possui grandes dimensões e diversas entradas alternativas, tornando a visitação do parque subestimada.

A caracterização e a sazonalidade observadas podem ser transportadas dos núcleos para os setores, que aglomeram os atrativos do parque, visando orientar a administração para realização de uma gestão estratégica, com o foco de ações direcionado para os setores de acordo com a época do ano, buscando uma melhoria na recepção dos visitantes, adequando o atendimento e estruturas com cada perfil e visando incrementar as atividades da UC, promovendo divulgação dos objetivos de conservação da unidade.

A partir da estruturação do uso público no PETP, foi sugerida a seguinte setorização: Educação Ambiental, Administração, Águas, Esportes e Montanha. Esta setorização pode ser ampliada, englobando outras partes do parque, como os municípios de Silva Jardim e Guapimirim e outros a serem definidos de acordo com a demanda de atividades. Como exemplos dessas demandas, tem-se: observação de aves, manifestações religiosas, pesquisa, fotografia, entre outros, sempre respeitando as normas e zoneamento da UC, evidenciando suas potencialidades e promovendo a integração de atividades de uso público.

Esta setorização inicial, baseada nos principais atrativos identificados na UC, visa facilitar a caracterização da visita e destacar as potencialidades do parque, podendo futuramente apresentar números concretos a partir de cadastramento de visitantes em pontos estratégicos de cada setor. Este agrupamento gera um novo ângulo de visão e visa promover a realização de gestão estratégica, direcionando ações de uso público e manejo para melhor recepção de visitantes. Futuramente a reunião das atividades por setor pode ser mais fundamentada e ajudar na divulgação do PETP, já que setores são mais atraentes do que uma atividade isolada, promovendo a visita em mais de um núcleo e município. Isso pode aumentar a qualidade e variedade da visita, o tempo de estadia, gerando renda para mais de um município.

\section{Referências bibliográficas}

BRASIL. LEI N. ${ }^{\circ}$ 9.985, de 18 de julho de 2000 - Institui o Sistema Nacional de Unidades de Conservação da Natureza e dá outras providências. Disponível em: < http://www.planalto.gov.br/ccivil_03/leis/19985.htm $>$.

\section{CAMPOS, R. M. O Parque Estadual dos Três (PETP) e sua inserção no contexto da conservação da natureza no estado do Rio de Janeiro. Niterói, 2007.}

EAGLES, P. F. J. International Trends in Parks Tourism. In: EUROPARC 2001. Matrei, Austria. v. 4, n. 17, Sep. 2001.

EAGLES, P. F. J.; McCOOL, S. F.; HAYNES, C. D. Sustainable Tourism in Protected

Areas: Guidelines for planning and management. Cambridge: IUCN, 2002.

FRANCIOLI, S. E.; MUÑOZ, M. M. Orígen de la biosfera en Chile Central. 2002.

Disponível em: <

http://www.geo.puc.cl/pdf/moreira/actualizacion_2012/LaCampanapag1_26.pdf $>$. Acesso em: 23 maio 2013. 
ICMBIO. 2013. Guia do visitante do Parque Nacional do Itatiaia. 2013. Disponível em: < http://www.icmbio.gov.br/parnaitatiaia/ >. Acesso em: 24 maio 2013.

INEA (Instituto Estadual do Ambiente). Plano de Manejo do Parque Estadual dos Três

Picos. 1. revis. 2009.

KEMOTO, S. M. Trilhas Interpretativas e sua relevância para a promoção da conservação: estudo de caso da trilha do Jequitibá. I Encontro Científico do Parque Estadual dos Três Picos. 2008. Disponível em: <

http://urutau.proderj.rj.gov.br/inea_imagens/downloads/pesquisas/PE_Tres_Picos/Ikemoto_20 08.pdf >. Acesso em: 22 maio 2013.

LORENZETTO, A. Turbinando o uso público em UCs do Rio de Janeiro. Disponível em: $<$ http://www.oeco.org.br/convidados-lista/27200-turbinando-o-uso-publico-nas-ucs-do-riode-janeiro >. Acesso em: 22 maio 2013.

OLIVEIRA, A. C. L. et al. Cadernos de Educação Ambiental. Ecoturismo, SMA.

Disponível em: < http://www.ambiente.sp.gov.br/wp-content/uploads/publicacoes/sma/5ecoturismo.pdf >. Acesso em: 23 maio 2013.

PADINI, H. Unidades de Conservação no Brasil: o caminho da Gestão para Resultados, estudo de caso 5.1; O Desafio do uso público nas Unidades de Conservação Brasileiras, 2012.

PAULO, S. P.; CARLOS, E. C. M. Caracterização dos visitantes do parque municipal da lagoa do Peri-Florianópolis-SC: uma contribuição metodológica para a gestão da visitação em unidades de conservação. 2010. Disponível em: 〈 http://www.univali.br/revistaturismo $>$.

PARQUES DA COPA 2014: Parques Estaduais do Rio de Janeiro. Disponível em: < http://download.rj.gov.br/documentos/10112/657214/DLFE-41811.pdf/10_PARQUES.pdf >. Acesso em: 22 maio 2013. 